Ophthalmologica 1985;190:1

\title{
In memoriam Jules François
}

Le 13 août 1984 est décédé à Zermatt, où il passait chaque année ses vacances, le profes-seur émérite Jules Francois.

Né le 12 mars 1907 à Gingelom, dans Tan-cien duché de Limbourg, il a fait ses etudes à Louvain et a été appelé en 1948 à la chaire d'ophtalmologie de Gand qu'il transforma rapidement en un centre d'ophtalmologie renommé dans le monde entier.

C'était un travailleur infatigable; sa devise était: travail. II se donna entièrement à

Tophtalmologie et consacra sa vie aux mala-des, à la recherche, à Гenseignement, à trans-mettre ses vastes connaissances au monde ophtalmologique.

Caractère ouvert, généreux qui avait be-soin de s'extérioriser, il est renommé, res-pecté, aimé.

Voyageur infatigable, il con-naissait $\Gamma$ ophtalmologie de tous les pays et savait renseigner, donner des conseils, arbi-trer. L'ophtalmologie était pour lui un apos-tolat.

Ses publications sont innombrables (1800) ainsi que ses livres (40 et plus) dans lesquels on trouve la synthese de ses travaux. II était president du Conseil International d'Ophtalmologie, du Conseil Européen, membre fondateur de $\Gamma$ Académie Internationale d'Ophtalmologie.

Couvert de distinctions, d'honneurs, doc-teur honoris causa de plus de 20 universités, récipiendaire de plus de cinquante médailles

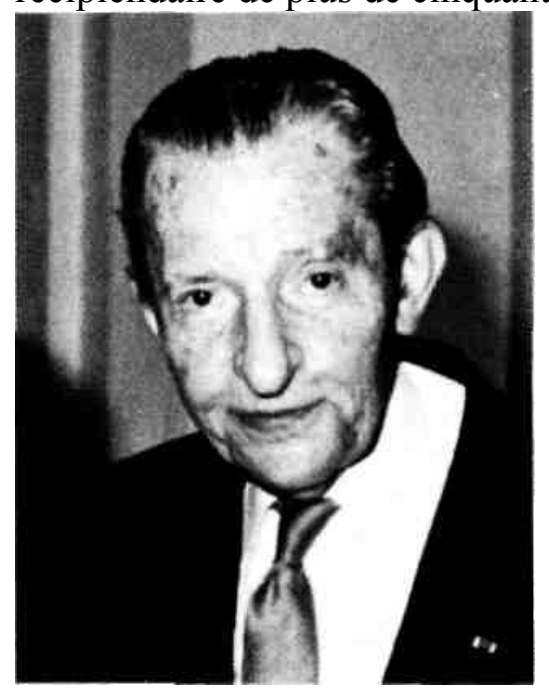

Jules Francois

d'or, dont la médaille Jules Gonin. Le roi des Beiges le fait baron.

Jules Francois a preside aux destinées de Tophtalmologie universelle, a su la conduire à son haut niveau actuel; il en a fait une grande famille. II a cultivé Гamitié, qu'il a donnée généreusement. Nous perdons un ami et le vide qu'il laisse sera difficile à combler.

O. Ophthalmologica exprime à la fille et à la famille de son rédacteur honoraire sa pro-fonde sympathie.

B. Streiff 
Lausanne 